\title{
STUDY OF URINE PH, HYPERCALCIURIA, URINARY TRACT INFECTION AND ITS CORRELATION WITH STONE COMPOSITION IN BHOPAL REGION
}

\author{
Mahendra Damor ${ }^{1}$, M. C. Songra², Naveen Kumar Patbamniya ${ }^{3}$ \\ ${ }^{1}$ Assistant Professor, Department of General Surgery, Gandhi Medical Collegel, Bhopal, M. P. \\ 2Professor and HOD, Department of General Surgery, Gandhi Medical College, Bhopal, M. P. \\ ${ }^{3}$ Assistant Professor, Department of General Surgery, Gandhi Medical College, Bhopal, M. P.
}

ABSTRACT BACKGROUND: This prospective case control study is an attempt to study the importance and significance of urinary
pH, urinary tract infection (Urinary Culture) and hypercalciuria and its correlation with stone composition in patients of urolithiasis.
METHODS: This prospective cases control study is done at the Department of Surgery, Gandhi Medical College \& Associated Hamidia
Hospital, Bhopal (M.P.) India from October 2013 to October 2014 . We have included 25 healthy persons as control group for the
comparison of study group i.e. patients of urolithiasis. RESULTS: Total (43.5\%) persons were having stones in upper urinary tract. The mean age (+/-SD) of the study group was 31.5 for the males and 34.5 for the females. In control group it was 30.4 males and 30.2 for the females. The overall ratio of M/F was 1.5:1.0 in stone former (Study group) group and 2.1:1.0 in control group. Most (82.5\%) of stone former persons were in lower and middle socioeconomic group. $65.2 \%$ persons in stone former group were taking water less than 2 liters per day while in normal control group it was $48 \%$. Milk and milk products consumption was very high in stone formers i.e. 34/46(73.9\%). Pain in the flanks is the first symptom of upper urinary tract calculi. Haematuria and burning during micturition were present in $75 \%$ and $50 \%$ patients respectively. Pain during micturition was in $75 \%$ of the stone formers. Urinary $\mathrm{pH}$ was mostly acidic in stone formers. The $\mathrm{pH}$ of urine in stone formers was $5.40 \pm 0.05$ whereas in control group it was $6.34 \pm 0.08$. In our study we found that most of the stones formed in normal acidic urine $\mathrm{pH}$ were composed of mainly calcium oxalate as dominant component while in alkaline urine at pH 6 to 8 triple phosphate is the major stone component. Uric acid is mainly present in stones formed in acidic urine. 24 Hours urine volume was significantly low in stone formers $(750 \pm 156 \mathrm{ml})$ than in normal individuals $(1250 \pm 250 \mathrm{ml})$. S. Calcium level was also raised marginally i.e. $1.1 \pm 0.7 \mathrm{mEq} / \mathrm{l}$ in $15.8 \%$ of the stone formers as compared to normal control group persons. $21.5 \%$ of the stone formers had slightly raised serum uric acid levels i.e. $7.7 \pm 0.3$. Urine culture was positive in $11 / 46$ stone former i.e. $26 \%$. While in normal control, it was $12 \%$ person having positive culture of urine. Proteus isolated in $54 \%$ cases of Urinary stones diseases at alkaline $\mathrm{pH}$ of urine and Klebsiella were isolated in $18 \%$ at $\mathrm{pH} \mathrm{7-8}$ and E. coli was isolated at normal pH of 5-6 with all the stones being composed of mainly calcium oxalate.

CONCLUSIONS: This prospective study offers better understanding and knowledge of the distribution of urolithiasis condition in this area of Bhopal allowing an estimation of its impact on society and also better planning of various preventing programmes.

KEYWORDS: Urolithiasis, Urosepsis,Urine PH, Hypercalciuria.

HOW TO CITE THIS ARTICLE Mahendra Damor, M. C. Songra, Naveen Kumar Patbamniya. "Study of Urine PH, Hypercalciuria, Urinary Tract Infection and its Correlation with Stone Composition in Bhopal Region". Journal of Evolution of Medical and Dental Sciences 2015; Vol. 4, Issue 88, November 02; Page: 15298-15304, DOI: 10.14260/jemds/2015/2175.

INTRODUCTION: Prevalence of urinary stones is very high in many parts of the World. It is a major health problem, with a significant proportion of the patients requiring extensive surgical procedure and a sizable minority losing a kidney. Urolithiasis or urinary tract stone effects people worldwide with the prevalence ranging from $1-20 \%$.(1) $^{(1 t}$ is a relevant clinical problem with a subsequent burden for health system. Recurrence rate of calcium oxalate stones is about $10 \%$ at one year, $35 \%$ at 5 years and $50 \%$ at 10 years. ${ }^{(2,3,4)}$ The etiology of urolithiasis is multifactorial including environmental, behavioral, genetic and metabolic, a number of epidemiological and experimental studies have identified risk factors of stone formation and recurrence.(5) Recurrence of stone formation increases the risk of renal dysfunction which can cause a complication of renal failure.

Financial or Other, Competing Interest: None.

Submission 08-10-2015, Peer Review 09-10-2015,

Acceptance 20-10-2015, Published 30-10-2015.

Corresponding Author:

Dr. Mahendra Damor,

F-4, Doctor's Quarter's, Idgah Hills,

Bhopal-462001.

E-mail:dr.mahendamor@gmail.com

DOI:10.14260/jemds/2015/2175.
In the patients of multiple recurrent stones. An imbalance of stone modulators (Promoters and inhibitors) in urine causes the development of the stones. Elevation of stone promoters (e.g.-calcium, oxalate, phosphate and uric acid) or reduction of the inhibitors (e.g.-Citrate, potassium, magnesium and) creates supersaturated urine, consequently, nuclear crystals aggregate and eventually calculi are formed. Metabolic abnormalities causing, an equity of the promoters and inhibitors such as hypercalciuria, hyperoxaluria, hyperuricosuria and hypocitruria have been considered as major metabolic risk for the formation of urinary stones.(5) Calcium containing stones are the most common renal stones. ${ }^{(6,7)}$ Metabolic abnormalities such as low volume urine in $24 \mathrm{hr}$ along with change in $\mathrm{pH}$ and urinary infections are supposed to be major risk factors. Urine analysis is important in determining urine pH. A 24 hour urinary analysis to evaluate important urinary metabolites is very important to access various metabolic abnormalities in urine. $(8,9)$ Urinary $\mathrm{pH}$ may vary from 4.5 to 8.0 . The average $\mathrm{pH}$ varies between 5.5 and 6.5. A urinary $\mathrm{pH}$ between 4.5 to 5.5 is considered acidic, where as a $\mathrm{pH}$ between 6.5 to 8.0 is considered alkaline. In patient with a presumed UTI, an alkaline urine with a $\mathrm{pH}$ greater than 7.5 suggests infection with a urea splitting organism, most commonly with Proteus. 


\section{Modern theories of Etiology include:}

- Super - saturation and crystallization theory.

- Inhibitor deficiency theory.

- Matrix initiation.

- Intranephronic and fixed nucleation.

- Extranephronic and free particle nucleation.

- Extranephronic and free particle nucleation.

The earliest type of stone known to effect human was the infection (struvite) stones. These account for 2 to $20 \%$ of all stones. Most common organism associated with struvite (Infection) calculi is proteus mirabilis. Urease containing bacteria are most frequently associated with stone formation.(10) Struvite stones are also associated with other urea splitting organisms such as Pseudomonas, Providencia, Klebsiella, Staphylococci and Mycoplasma. The knowledge of these metabolic abnormalities is very important in the prevention and treatment of urolithiasis. The present study is an attempt to study the importance and significance of urinary $\mathrm{pH}$, urinary infection and hypercalciuria in patients of urolithiasis in Bhopal region.

METHODS: This prospective cases control study was carried out in Department of Surgery, Gandhi Medical College \& Associated Hamidia Hospital, Bhopal (M.P.) India from October 2013 to October 2014.

\section{PATIENTS SELECTION:}

\section{Inclusion Criteria:}

1. Both male and female between age of 1 to 70 yrs.

2. All patients admitted to hospital with renal, ureteric and vesical calculus which were radiologically confirmed.

\section{Exclusion Criteria:}

1. Patient who had history of bowel disease, renal tubular acidosis and urinary tract abnormalities.

2. Patients with other causes of sepsis.

Control Group: 25 healthy individuals $(17$ males and 8 females) were included in the control group. All controls were free from the diseases including urolithiasis.

Collection of Samples: The 24 hours urine samples were collected from all patients. It was collected in wide capped clean transparent graduated plastic collection bottle. Volume of specimen was noted and used for analysis.

For pH determination morning samples were used.

Method : The on off switch of the instrument is set on a start position and power cord is connected with mains to get it on. 5 minutes period is allowed to warm up the $\mathrm{pH}$ meter, and its needle adjustment is verified at $\mathrm{pH}$ scale 7.0. Then prior this the instrument electrodes are regenerated as follows.

1. Both the electrodes including the reference electrodes are put in $0.1 \mathrm{NaCl}$ solutions for over night. The electrodes are thoroughly washed with distilled water in one of the electrodes saturated KCL solution is filled inside with the help of capillary pipettes.
Standardization: The $\mathrm{pH}$ meter is standardized with a series of standard buffer solution of $\mathrm{pH} 0.07$ and 9.2 to read the $\mathrm{pH}$ of each standard buffer values.

Measurement of Urinary pH : Electrodes were thoroughly washed with glassed distilled water while the instrument's $\mathrm{pH}$ measurement knob was at start position. The $\mathrm{pH}$ of distilled water was checked by selecting the knob to $0-8 \mathrm{pH}$ scale. In all cases, the $\mathrm{pH}$ of distilled water was around 5.8 to 6.0. The instrument $\mathrm{pH}$ scale knob was put al neutral point. The $\mathrm{pH}$ of standard buffer checked and any deviation from the $\mathrm{pH}$ scale of 4 was corrected with the standard knob. Against, the electrodes were washed thoroughly with distilled water and in similar manner, the $\mathrm{pH}$ of urine sample were recorded. Electrodes were carefully washed with distilled water between each reading.

The biochemical parameters Calcium was analyzed using Sigma Diagnostics assay kits.

For urine culture, Mid - stream sample of early morning urine were collected and sent to the laboratory and processing done by conventional methods and recorded.

\section{Media Used:}

1. MacConkey Agar of CLED Agar was used in most of the cases.

2. Peptone water.

3. Nutrient Broth.

4. Nutrient Agar.

5. A drop of the sample was taken with the help of nichrome wire loop on the MacConkey's media plate and was well smeared on it.

Incubation: Inoculated media was placed in an incubator at 37 degree $C$ and kept for 24 hours only. If no growth took place after this period, the culture was labeled as sterile.

\section{Isolation of the organisms}

The organism were identified and confirmed after seeing:

1. The colony character

2. The morphology of the organism (Gram Staining)

3. Biochemical reaction.

From the cultured growth of organisms a portion of the colony was transferred to the peptone water (Peptone $1 \%, \mathrm{NaCl}$ $5 \% 100$ c.c.) and kept in the incubator at the temperature of 37 deg. $c$ for 2-4 hours.

\section{This sub culture was used for:}

1. Observing motility by hanging drop method.

2. Various biochemical reactions like, fermentation of various sugars done.

3. To test the sensitivity of various drugs.

Biochemical Reaction:

1. One or two drops of the culture suspension from the peptone were transferred to the 5 tubes containing glucose, lactose, sucrose, mannitol and dulcitol. The reactions were noted for acid formation or acid and gas formation.

2. Test for indole production, catalase, oxidase, IMVUC were also done. 
Stone specimens were obtained by open surgery or endoscopic procedures, washed to remove debris, dried and sent for the biochemical analysis by FTIR caiorimetric technique.

We have also taken Blood samples of each individual for the estimation of Serum Calcium, Serum Uric Acid, Blood Urea and Serum Creatinine. The value of each parameter was compared between controls and study group.

The results were expressed as mean \pm standard deviation and statistical analysis of the data was performed by student's unpaired t-test.

RESULTS: The present study was carried out on 71 patients over a period of 12 months from October 2013 at the Department of Surgery, Gandhi Medical College \& Associated Hamidia Hospital, Bhopal (M.P.) India. 46 patients presented to us with various symptomatology of urinary calculi, which were confirmed radiologically to be suffering from urolithiasis. Each case has been analyzed for clinicoetiological features namely demographic profile, symptomatology, co-morbid conditions, clinical features various laboratory parameters. The patients were divided into 2 groups control group ( $\mathrm{N}=25)$ and study group $(\mathrm{N}=46)$.

DISCUSSION: Urinary stone disease is a major health problem in many parts of the world and endemic in India.

Despite the introduction of non invasive techniques for the removal of the stones, urinary stones remain the major source of morbidity. This is partly because complete pathogenesis and thus prevention of urolithiasis remains to be clarified. This is not only because of complexity of the kidney as a functionary organ, involved in a multitude of body processes maintaining the milieu interior, but also due to an ever-changing ionic atmosphere intarenally.

Distribution of Calculi in the Urinary Tract: Over all distribution of stones within the urinary tract, kidney stones are common among the man. The relative higher number of ureteric calculi found in man correspond to an increased tendency to spontaneous passage. A total number of 71 persons (46-study group and 25 control normal group.) were studied out of which 20 stone former were of Upper urinary tract and 26 belongs to Lower Urinary tract.

Age and Sex: From a variety of studies it emerges that clinical stone disease of the urinary tract clearly affects men more frequently than women. It would appear that the ratio of male to female is 3:1 (Fetter et al;1963).(11) Among the younger partients in the cohort of Ljunghall et at (1977).(12) 328 patients had their first stones before their 30th year This figure was only $1.4 \%$ the older patients.

The author therefore suggested that there has been an accumulative increase in the incidence of urolithiasis in recent year. The peak incidence of first episode lies between 2nd to 4 th decades of life. In our study sex ratios was 1.5:1 in stone former group. Bladder calculi were discussed in great detail at a symposium in Bangkok (Von Reen at al; 1972).(13,14) authors reported on the situation in India Pakistan, Thailand, Iran and other countries generally starting that $90 \%$ of patients are under the age of 5 (Singh 1972).(15)
Socio-economic Status: Socio-economic conditions have long been known to influence. human health for the mjority of the world's people. Health status is determined primarily by their level of socio-economic development e.g. per capita GNP, ducation, Employment, housing, the political system of the country.

A second major factor influence health status is education pecially female education. Employment productive work promotes health because the unemployed usually show a higher incidence of ill health. In my study, more than $80 \%$ people belonged to middle and lower socioeconomic group.

Dietary Factors : Little doubt can exist that dietary intake of various food and fluids which result in the greater urinary excretion of the substance that produce stone, has a significant. effect/or > the incidence of urinary clculi. Robertson at al (1979).(16) drew attention to the relationship between the incidence of stones and the level of consumption of animal protein in the significant increse in urinary calcium, oxalate and uric acid excretion accompanies a high protein diet in both stone former and volunteers.

Certainly the calciuretic effect of carbohydrate ingestion is well documented (Hodgkinson) show that patients with calcium exalate stones exhibited an exaggerated calcuretic response often in oral carbohydrate load by comparison with non-stone forming control subjects. Table 5 in my series showed relation between dietary hbit and urolithiasis. 50\% of stone former persons were pure vegetarian and $30 \%$ werenon vegetarian and $20 \%$ were occasional non vegetarian.

Symptoms: Pain as a clinical manifestation of urolithiasis varies considerably from case to case depending on site, size, surface structure and mobility of stone (Marberger at al 1983).(17) Stone patients most commonly present with classical ureteric colic which either may be heralded by dragging discomfort or may come on suddenly. Severe pain is due to the sudden arrest of calculus on its way through the urinary tract being caused primarily by local irritation at the site of impaction.

Paint will be localized and radiate quite differently, depending on the exact site of impaction, similar events follow impaction of stones in the upper ureter but there is usually a complaint of additional pain radiating along the course of the groin or genitalia. In our series we showed symptoms in upper and lower urinary tracts separately.

First rank symptoms of upper urinary tract wer pain in abdomen or flanks which were present in $100 \%$ of cases, Second rank symptom of upper urinary tract stone disease was humaturia which was present in $75 \%$ of cases. Third rank of symptoms of upper urinary tract disease was burning in micturition which were present in $30 \%$ of cases. First symptom of lower urinary tract stones disease were pain during micturition. Second symptom was Suprapubic pain which was present in $50 \%$ of cases. Third rank of symptoms of lower urinary tract stones diseases was hematuria which was present in $30 \%$ of cases.

Urinary pH determination can be helpful in the management and treatment of both urinary tract and urinary calculus disease in a presumed urinary tract infection and alkaline urine (>7.5) suggest an infection with a urea splitting organism most commonly proteus mirabilis, Klebsiella, Pseudomonas and 
staphylococcal may also produce urea se and cause an alkaline urine $\mathrm{pH}$. Patient with infection from urea se producing organisms are less soluble in alkaline urine. Calcium phosphate forms at $\mathrm{pH}$ of 6.6 or higher, whereas magnesium, ammonium, ammonium phosphate precipitate at a $\mathrm{pH}$ of 7.2 or higher. Therefore the combination of urinary tract infection and struvite calculus formation can readily occur.

Urinary $\mathrm{pH}$ determination helps to confirm the diagnosis of renal tubular acidosis. The inability to acidify urine below a $\mathrm{pH}$ of 5.5. Urine $\mathrm{pH}$ is classically acidic in patients with uric acid and Cystine stone. Alkalization of the urine is important medical therapy for these patinets.

In our study, table 9 showed urinary $\mathrm{pH}$ and urolithiasis in $10 \%$ of cases of upper urinary tract stone were urine $\mathrm{pH}$ was acidic, $40 \%$ urine $\mathrm{pH}$ was lkaline.

Urinary Tract Infection: The importance of the urea splitting bacteria in the formation of infected calculi suggested that an enzyme produced by gram negative bacilli was capable of converting urea in to ammonia. This urea se cause in increase alkalinity and lead to the precipitation of calcium magnesium ammonium salt. Infection as the cause of magnesium, ammonium phosphate urinary calculi must be differentiated from infection as a result of treatment of previous calculi of different composition.

Individual with chronic urinary infection should always be considered to have a higher risk of formation of urinary calculi then individual without such infection.

In my study table 12 showed urinary tract infection and $\mathrm{pH}$.

Urinary Metabolic Abnormities:In our study twenty four hour urinary calcium, were higher in stone formers. These are the major risk factors in first time stone formers and in recurrent stone formers. Means daily urinary calcium excretion in the stone formers was higher than normal control persons. Increased urinary calcium levels as observed in our study plays an important role in the recurrence of stone disease. We did not study the cause of hypercalciuria, therefore we can not stipulate whether it was absorptive hypercalciuria, renal leak hypercalciuria or Resorptive hypercalciuria as the major determinant factor of stone recurrence.

In present study urinary $\mathrm{pH}$ of stone formers was $5.30+0.05$. This indicates that that at this $\mathrm{pH}$ calcium oxalate solubility is minimum and hence urine gets supersaturated with calcium oxalate. Although $\mathrm{pH}$ was favourable for stone formation in control group even though the stone was not formed, it may be due to high level of urinary inhabitators such as citrate. The urine excretion was signifcantly low in the kanpur region possibly people don't drink much water and also because of slightly warm and humid atmosphere.

Urine culture report revealed slightly positive culture in stone former especially in the stone formers of rural areas. on the basis of urinary abnormalities, dietary modifications such as low intake of tomatoes, green vegetables, salts and avoidance of open milk are important preventive measures. Soft water drinking and adequate quantity can be suggested to stone formers so as to prevent further stone formation and to decrease prevalence rate in this Kanpur region of Uttar Pradesh of India.
Morphologically only 7/20 upper urinary tract calculi were staghorn shape (struvite), while rest and irregular shape, black to brown in colour, hard While most of the bladder calculi were solitary, uneven black - brown 10/14, rest were multiple chalky white. The urinary stones analyzed showed that calcium oxalate was present along with other substance in 95\% stones, while calcium phosphate was present in $42 \%$ stones in combination with calcium oxalate and uric acid. Uric acid as dominant component was found only in 5\% cases.

SUGGESTIONS: The following suggestions are made to decrease the incidence of urolithiasis in the Bhopal region of Madhya Pradesh.

1. Awareness of this urolithiasis in general public.

2. Proper water intake (At least 2.5lit/day) because most of stone formers are having very less amount of water intake and so they have less urine formation per day.

3. Avoidance of adulterated milk and milk products.

4. Dietary modifications such as avoidance of high intake of rice (Unpolished rice), green vegetables, tomatoes.

5. Water consistency should be examined regularly. Biochemical filters should be used for better public health.

We also consider that there is a need for fully equipped urologic department and clinics in this area to manage to high prevalence of urolithiasis in the Bhopal region of Madhya Pradesh of India.

CONCLUSION: This prospective study offer better understanding and knowledge of the distribution of urolithaisis condition in the areas of Bhopal, allowing and estimation of its impact on society and also better planning of various preventing programmes.

\section{BIBLIOGRAPHY:}

1. Stamatelou KK, Francis ME, Jones CA, Nyberg LM, Curhan GC. Time trends in reported prevalence of kidney stones in the United States: 1976-1994. Kidney Int. 2003; 63(5):1817-23.

2. Johnson CM, Wilson DM, O'Fallon WM, Malek RS, Kurland LT. Renal stone epidemiology: a 25-year study in Rochester, Minnesota. Kidney Int. 1979; 16(5):624-31.

3. Novak TE, Lakshmanan Y, Trock BJ, Gearhart JP, Matlaga BR. Sex prevalence of pediatric kidney stone disease in the United States: an epidemiologic investigation. Urology. 2009; 74(1):104-7.

4. Trinchieri A, Ostini F, Nespoli R, Rovera F, Montanari E, Zanetti G. A prospective study of recurrence rate and risk factors for recurrence after a first renal stone. J Urol 1999; 162(1):27-30.

5. Curhan GC. Epidemiology of stone disease. Urol Clin North Am. 2007 Aug; 34(3):287-93.

6. Singhal PC, Jacobson AL, Mandin H, Hyne JB. Calcium dynamics in idiopathic calcium stone formers. Biochem Med. 1983; 29(1):122-33.

7. Schlieper G, Westenfeld R, Brandenburg V, Ketteler M. Inhibitors of calcification in blood and urine. Semin Dial. 2007; 20(2):113-21.

8. Pubmed search engine; http://www.ncbi.nlm.nih.gov/pubmed/ 
9. Ng RH, Menon M, Ladenson JH. Collection and handling of 24-hour urine specimens for measurement of analytes related to renal calculi. Clin Chem. 1984; 30(3):467-71.

10. Griffith DP. Urease stones. Urol Res. 1979; 7(3):215-21.

11. Fetter TR. Statistical analysis of patients with ureteral calculi. JAMA1963;186:21-3.

12. Ljunghalls,waern AU. Urinary electrolytes in renal stone formers and healthy subjects. A population study of 60yrs old men.scand j urol nephrol. 1977;41.

13. Valyasevi, A. and Van Reen, R.) Pediatric bladder stone disease; current status of research. J. Pediatric.1968,72:546.

14. Van Reen, R. Geographical and nutritional aspects of endemic stones, in urinary calculus international urinary stone conference. Edited by J. Gwynne Brockis and Birdwell Finlayson. Littleton, PSG Publishing, 1981, p.177.
15. Singh, S.M. Idiopathic urinary bladder stone disease in India; historical aspects, geographical incidence, and clinical features, in idiopathic urinary bladder stone disease. Sponsored by John E. Fogarty International Center. Edited by Robert Van Reen. Washington, DHEW Publication, 1977, p. 209.

16. Robertson W.G,P.J Heyburn,M.Peacock,F.A Hanes and Swaminathan 1979b.The effect of high animal protein intake on the risk of calcium stone formation in the urinary track . clin.scin 57:285-288.

17. Marberger, Michael. "Disintegration of renal and ureteral calculi with ultrasound." The Urologic clinics of North America 10, no. 4 (1983): 729-742.

\begin{tabular}{|c|c|c|c|c|}
\hline \multicolumn{2}{|c|}{ Upper Urinary Tract } & \multicolumn{3}{|c|}{ Lower Urinary Tract } \\
\hline Renal & Upper & Middle/Lower & Bladder & Urethral \\
\hline 18 & 02 & 09 & 14 & 03 \\
\hline \multicolumn{3}{|c|}{ Table 1: Location of Calculus (N=46 - Study Group) } \\
\hline
\end{tabular}

Total 20/46 (43.5\%) persons were having stones in upper urinary tract. 4/14 patients of urinary bladder stones were present in childhood age.

\begin{tabular}{|c|c|c|c|c|}
\hline \multicolumn{2}{|c|}{ Study Group (n=46) } & \multicolumn{3}{c|}{ Control Group (n=25) } \\
\hline Age (yrs) & Male & Female & Male & Female \\
\hline $0-10$ & 2 & - & 2 & - \\
\hline $11-20$ & 2 & - & 2 & 1 \\
\hline $21-30$ & 3 & 2 & 7 & 3 \\
\hline $31-40$ & 7 & 6 & 3 & 3 \\
\hline $41-50$ & 10 & 8 & 2 & 1 \\
\hline $51-60$ & 3 & 2 & 1 & - \\
\hline $61-70$ & 1 (Recurrence) & - & - & - \\
\hline \multicolumn{3}{|c|}{ Table 2: Age Wise Distributions of Individuals } \\
\hline
\end{tabular}

Most of upper urinary tract stones lie in age group 21-40 years. The mean age (+/- SD) of the study group was 31.5 for the males and 34.5 for the females. In control group it was 30.4 males and 30.2 for the females.

\begin{tabular}{|c|c|c|}
\hline Sex & Study Group (n=46) & Control Group (n=25) \\
\hline Male & 28 & 17 \\
\hline Female & 18 & 8 \\
\hline \multicolumn{2}{|c|}{ Table 3: Sex Wise Distribution (N=46) } \\
\hline
\end{tabular}

The overall ratio of M/F was 1.5:1.0 in stone former group and 2.1:1.0 in control group.

\begin{tabular}{|c|c|c|}
\hline & Study group (n=46) & Control Group (n=25) \\
\hline Lower socio-economic & 21 & 11 \\
\hline Middle Socio-economic & 17 & 10 \\
\hline High Socio economic & 8 & 4 \\
\hline \multicolumn{2}{|c|}{ Table 4: Urban/Rural Distribution } \\
\hline
\end{tabular}

Most (82.5\%) of study group persons were from lower and middle socioeconomic group.

\begin{tabular}{|c|c|c|c|}
\hline & $\begin{array}{c}\text { Water intake } \\
\text { less than 2 } \\
\text { liter/day }\end{array}$ & $\begin{array}{c}\text { Water intake } \\
\text { more than } \\
\text { liter/day }\end{array}$ & P value \\
\hline Study Group (n=26) & $30 / 46(65.2 \%)$ & $16 / 46(34.8 \%)$ & Not Significant \\
\hline Control Group (n=25) & $12 / 25(48 \%)$ & $13 / 25(52 \%)$ & $<0.01$ \\
\hline \multicolumn{4}{|c|}{ Table 5: Distribution According to Water Intake/Day } \\
\hline
\end{tabular}


$65.2 \%$ persons in study group were taking water less than 2 liters per day while in control group it was $48 \%$. So, over all water intake was comparatively less in study group.

\begin{tabular}{|c|c|c|}
\hline & Study Group (n=46) & Control Group (n=25) \\
\hline Non-vegetarian & $28 / 46(60.8 \%)$ & $11 / 25(44.0 \%)$ \\
\hline Vegetarian & $18 / 46$ & $14 / 25$ \\
\hline \multicolumn{2}{|c|}{ Table 6: Distribution according to Dietary Habits } \\
\hline
\end{tabular}

Non-vegetarian patients were $60.8 \%$ in study group. Rice intake was high $40 \%$ of daily diet in case group. General milk and milk products consumption was very high in stone formers i.e. $34 / 46(73.9 \%)$.

\begin{tabular}{|c|c|c|c|}
\hline Sl. No. & Symptoms & Number of cases & Percentage \\
\hline 1 & Pain in abdomen of Flanks & 20 & $100 \%$ \\
\hline 2 & Burning pain during micturition & 10 & $50 \%$ \\
\hline 3 & Haematuria & 15 & $75 \%$ \\
\hline 4 & Fever with rigor & 5 & $250 \%$ \\
\hline 5 & Nausea and Vomiting & 3 & $105 \%$ \\
\hline \multicolumn{2}{|c|}{ Table 7: Studies in Urolithiasis - Symptoms in Upper Urinary Tract Stones } \\
\hline
\end{tabular}

Pain the flanks or abdomen is the first symptom of upper urinary tract calculi $100 \%)$ occurred in all stone study group. Haematuria and burning during micturition were present in $75 \%$ and $50 \%$ patients respectively.

\begin{tabular}{|c|c|c|c|}
\hline Sl. No. & Symptoms & Number of cases & Percentage \\
\hline 1 & Pain during micturition & 15 & $75 \%$ \\
\hline 2 & Pain in supra pubic Region & 5 & $25 \%$ \\
\hline 3 & Haematiuria & 2 & $10 \%$ \\
\hline 4 & Fever with rigor & 2 & $10 \%$ \\
\hline 5 & Retention off Urine & 1 & $5 \%$ \\
\hline \multicolumn{2}{|c|}{ Table 8: Studies in Urolithiasis - Symptoms in Lower Urinary Tract Stones } \\
\hline
\end{tabular}

Pain during micturition was $75 \%$ in study group. Next important symptom was pain in supra pubic region occurring in $25 \%$ patients.

\begin{tabular}{|c|c|c|}
\hline Urinary pH & Study Group (n=46) & Control Group (n=25) \\
\hline $3-1$ & - & - \\
\hline $4-5$ & 11 & 4 \\
\hline $5-6$ & 18 & 7 \\
\hline $6-7$ & 12 & 13 \\
\hline $7-8$ & 5 & 1 \\
\hline \multicolumn{2}{|c|}{ Table 9: Studies of Urinary PH } \\
\hline
\end{tabular}

Urinary pH was mostly acidic in study group. 21 persons were having $<5.5 \mathrm{pH}$ in study group. While in control group, $52 \%$ persons were having $\mathrm{pH}$ between 6-7. The $\mathrm{pH}$ of urine in study group was $5.40 \pm 0.05$ whereas in control group it was $6.34 \pm 0.08$.

\begin{tabular}{|c|c|c|}
\hline Urinary pH & $\begin{array}{c}\text { Upper Urinary tract } \\
\text { stones }\end{array}$ & Lower Urinary stones \\
\hline $3-4$ & - & - \\
\hline $4-5$ & 5 & 6 \\
\hline $5-6$ & 7 & 11 \\
\hline $6-7$ & 5 & 7 \\
\hline $7-8$ & 3 & 2 \\
\hline Total & $\mathbf{2 0}$ & $\mathbf{2 6}$ \\
\hline \multicolumn{2}{|r|}{ Table 10: Studies of Urinary PH in Study Group } \\
\hline
\end{tabular}

$40 \%$ cases of UUT were alkaline and $25 \%$ cases of UUT were acidic. $30 \%$ cases of LUT were alkaline and $25 \%$ cases had acidic urine.

\begin{tabular}{|c|c|c|}
\hline Urinary pH & Stone Composition & No. of Stones \\
\hline $3-4$ & None & 10 \\
\hline $4-5$ & $\mathrm{CaOx}+\mathrm{UA}$ & 17 \\
\hline $5-6$ & $\mathrm{Caox}+\mathrm{CaP}+\mathrm{UA}$ & 10 \\
\hline $6-7$ & $\mathrm{CaP}+\mathrm{CaOx}$ & 9 \\
\hline $7-8$ & $\mathrm{CaP}+$ Amon. P + CaOx & \\
\hline \multicolumn{2}{|c|}{ Table 11: Chemical Nature of Stone and Urine PH } \\
\hline
\end{tabular}

In our study we found that most of the stones formed in normal acidic urine pH were composed of mainly calcium oxalate as dominant component while in alkaline urine at pH 6 to 8 triple phosphate is the major stone component. Uric acid is mainly present in stones formed in acidic urine. 


\begin{tabular}{|c|c|c|}
\hline Urinary VOLUME & STUDY GROUP & CONTROL GROUP \\
\hline $500-1000$ & 30 & 6 \\
\hline $1000-1500$ & 8 & 8 \\
\hline $1500-2000$ & 6 & 7 \\
\hline$>2000$ & 2 & 4 \\
\hline \multicolumn{2}{|r|}{ Table 12: 24 Hour Collected Urine Analysis for Urinary Volume } \\
\hline
\end{tabular}

$30 / 46$ persons in study group were having 24 hour collected urinary volume of less than $1000 \mathrm{ml}$. 24 Hours urine volume was significantly low in study group $(750 \pm 156 \mathrm{ml})$ than in normal individuals $(1250 \pm 250 \mathrm{ml})$.

\begin{tabular}{|c|c|c|}
\hline Parameters & Study Group & Control Group \\
\hline $\begin{array}{c}\text { Blood Urea } \\
\text { (Normal 25-45mg \%) }\end{array}$ & $34 \pm 34$ & $30 \pm 2.5$ \\
\hline $\begin{array}{c}\text { Serum Creatinine } \\
\text { Normal (0.1-1.4 mEq/lt) }\end{array}$ & $0.95 \pm 0.7$ & $0.82 \pm 0.7$ \\
\hline $\begin{array}{c}\text { Serum Calcium } \\
\text { Normal (9-11mg\%) }\end{array}$ & $8.9 \pm 1.4$ & $7.92 \pm 1.3$ \\
\hline $\begin{array}{c}\text { Serum Uric Acid } \\
\text { Normal Value (3-6.5\%) }\end{array}$ & $6.43 \pm 1.2$ & $4.58 \pm 0.7$ \\
\hline \multicolumn{3}{|c|}{ Table 13: Blood Chemistry } \\
\hline
\end{tabular}

Blood Urea analysis showed normal values in both groups although $12.5 \%$ in study group were having marginally raised blood urea.

S. Calcium level was also raised marginally i.e. $1.1 \pm 0.7 \mathrm{mEq} / \mathrm{l}$ in $15.8 \%$ in the study group as compared to control group.

$21.5 \%$ of the study group had slightly raised serum uric acid levels i.e. $7.7 \pm 0.3$.

\begin{tabular}{|c|c|c|}
\hline Urine Culture & Study Group & Control Group \\
\hline Positive & $11 / 46$ & $3 / 25$ \\
\hline Negative & $33 / 46$ & $22 / 25$ \\
\hline \multicolumn{3}{|c|}{ Table 14: Bateriological Study of Urine } \\
\hline
\end{tabular}

Urine culture was positive in $11 / 46$ study group i.e. $26 \%$.

\begin{tabular}{|c|c|c|c|c|c|}
\hline Urinary pH & No. of Cases & E.coli & Proteus & Klebsiella & Staphylococcus \\
\hline $4-5$ & - & - & - & - & - \\
\hline $5-6$ & 2 & 2 & - & - & - \\
\hline $6-7$ & 1 & 1 & - & - & - \\
\hline $7-8$ & 8 & - & 6 & 4 & - \\
\hline \multicolumn{7}{|c|}{ Table 15: Bateriological Study in Study Group } \\
\hline
\end{tabular}

Isolated Bacteria is urinary tract stones (Total No. of Non-sterile - 11)

Proteus isolated in 54\% cases of stones diseases having alkaline $\mathrm{pH}$ of urine, Klebsiella were isolated in 18\% at pH 7-8 and E. coli was isolated at normal pH of 5-6 all the stones being composed of mainly calcium oxalate.

\begin{tabular}{|c|c|c|}
\hline Urinary Calciummg/day & Study Group (n=46) & Control Group (n=25) \\
\hline $100-150$ & $7(15.4 \%)$ & $3(12 \%)$ \\
\hline $150-200$ & $10(21.7 \%)$ & $13(52 \%)$ \\
\hline $200-250$ & $10(21.7 \%)$ & $7(28 \%)$ \\
\hline $250-300$ & $15(32.6 \%)$ & $2(8 \%)$ \\
\hline $300-350$ & $4(8.6 \%)$ & - \\
\hline \multicolumn{2}{|c|}{ Table 16: Distribution according to 24 hours collected urinary calcium level } \\
\hline
\end{tabular}

$41 \%$ of the study group had more than $250 \mathrm{mg} /$ day urinary calcium level. This shows the increase hypercalciuria in stone formers. While in controls $36 \%$ were having more than $250 \mathrm{mg}$ /day urinary calcium level.

\begin{tabular}{|c|c|c|}
\hline Stones Types & Number of Stones & Percentage \\
\hline $\mathrm{CaOx}+\mathrm{CaP}$ & 10 & $20.9 \%$ \\
\hline $\mathrm{CaOx}+\mathrm{CaP}+\mathrm{UA}$ & 9 & $16.2 \%$ \\
\hline $\mathrm{CaOx}+\mathrm{UA}$ & 25 & $58.5 \%$ \\
\hline $\mathrm{CaP}+\mathrm{UA}$ & 2 & $5.2 \%$ \\
\hline \multicolumn{3}{|c|}{ Table 17: Stone Analysis } \\
\hline
\end{tabular}

CaOx-Calcium Oxalate, Calcium Phosphate, UA - Uric Acid

The urinary stones analyzed showed that calcium oxalate was present along with other substance in $95 \%$ stones, while calcium phosphate was present in $42 \%$ stones in combination with calcium oxalate and uric acid. 